\title{
Controversial aspects in the diagnosis and management of Marshall syndrome
}

\author{
Controverse de diagnostic și tratament în sindromul Marshall
}

Veronica Epure ${ }^{1,2}$, Dan Cristian Gheorghe ${ }^{1,2}$
1Spitalul Clinic de Urgenţă pentru Copii "M.S. Curie“, Bucureşti, România
2Universitatea de Medicină şi Farmacie "Carol Davila", Bucureşti, România
ABSTRACT
Defined by recurrent febrile episodes af angina, adenitis and stomatitis, Marshall syndrome is frequently
encountered in clinical practice in children. The diagnosis is clinical, aided by the dramatic resolution of the
symptoms after administration of oral cortisone. The authors report 2 cases of Marshall syndrome and dis-
cuss their treatment, based on clinical datas from literature and their own experience in a children emergen-
cy department.

Keywords: Marshall syndrome, angina, adenitis, tonsillectomy, oral cortisone

\begin{abstract}
REZUMAT
Caracterizat prin episoade febrile şi repetitive de angină acută, stomatită şi adenită laterocervicală, sindromul Marshall este din ce în ce mai des întâlnit în practica pediatrică. Este un diagnostic clinic de excludere, completat printr-o probă terapeutică - răspunsul spectaculos la administrarea corticoterapiei. Autorii prezintă două cazuri de sindrom Marshall şi discută probleme legate de tratament, revizuind literatura de specialitate şi experienţa proprie dintr-un serviciu pediatric de urgenţă.
\end{abstract}

Cuvinte cheie: sindrom Marshall, angină acută, adenită, amigdalectomie, corticoterapie orală

\section{INTRODUCERE}

Descris de Marshall în 1987 (1-3), sindromul omonim sau faringita acută recurentă (PFAPA: periodic fever, aphtous stomatitis, pharyngitis, cervical adenitis) este o afecţiune specific pediatrică (de obicei, apare la copiii sub 5 ani), caracterizată prin episoade febrile recurente asociate cu simptome de faringită şi/sau stomatită şi adenită laterocervicală (2). Episoadele febrile apar periodic (intervalul de recurenţă variază de la 2 la 12 săptămâni, în general este de 4-5 săptămâni). Interepisodic, pacientul se prezintă şi dezvoltă perfect normal (1). Este necesară excluderea neutropeniei ciclice şi a altor diagnostice diferenţiale: artrita reumatoidă juvenilă, neutropenia ciclică, boala Behçet, febra mediteraneană familială, hiperglobulinemia D $(2,4,5)$.
Principalul diagnostic diferenţial se face cu amigdalita cronică cu recurenţe frecvente; în cazul sindromului Marshall, recurenţele sunt periodice (apar regulat la 3-5 săptămâni), răspunsul la corticoterapie este dramatic, tratamentul pe termen scurt diferă (corticosteroizii orali versus antibiotice şi AINS); tratamentul pe termen lung este acelaşi (amigdalectomie) $(2,4,6)$.

Mai recent, autorii consideră că diagnosticul PFAPA poate fi extins la orice copil care prezintă cel puţin 5 episoade febrile periodice fără altă explicaţie, chiar şi în absenţa faringitei, stomatitei sau adenitei laterocervicale şi chiar şi la copiii în vârstă de peste 5 ani (7) sau la adultul tânăr $(8,9)$.

Etiologia sindromului Marshall este necunoscută $(2,4,6)$; nu este de cauză infecţioasă. Faptul că amigdalectomia tratează eficient sindromul duce 
la concluzia că sindromul este declanşat de un proces imunologic cu debut la nivelul parenchimului amigdalian (2).

Tratamentul sindromului Marshall ridică încă unele controverse $(1,2,4,7,10)$. Unii autori constată că antiinflamatoarele nesteroidiene, aciclovirul şi antibioticele sunt ineficiente; administrarea de corticosteroizi per os în doză unică sau două doze (prednison $1 \mathrm{mg} / \mathrm{kgc}$; dexametazonă $0,25-0,5 \mathrm{mg} /$ kgc la copii; 60 mg prednison doză unică la adult) $(2,8)$ rezolvă dramatic simptomele în episodul febril. Aceasta este, de altfel, proba terapeutică, esenţială în diagnosticul sindromului - Padeh stipula în 1999 doze mai crescute de prednison, $2 \mathrm{mg} / \mathrm{kgc}$ doză unică (11). Corticosteroizii nu previn recurenţele febrile ulterioare, chiar pot scurta durata perioadelor asimptomatice, iar efectele adverse sunt redutabile (12). Autorii descriu tratamente alternative cu cimetidină (antagonist $\mathrm{H} 2$ ) $(5,10)$, colchicină, montelukast $(2,4,12)$.

Eficienţa amigdalectomiei în sindromul Marshall a fost descrisă pentru prima dată de Abramson (1989) la 4 copii cu faringită recurentă $(2,4,13)$, apoi studiată pe serii mai mari de până la 500 de pacienţi (6); eficienţa este de aproximativ $90 \%$ (în $10 \%$ dintre cazuri se ameliorează puţin sau deloc simptomele după amigdalectomie; la unii pacienţi pot persista şi dincolo de pubertate) $(2,6,8)$.

Este interesant că afecţiunea se autoremite spontan după câţiva ani la 40-50\% dintre pacienţi $(1,2,6,9)$, dar poate evolua pe o perioadă de 5-10 ani (11).

\section{PREZENTĂRILE CAZURILOR}

Pe o perioadă de 3 ani, am diagnosticat şi adenoamigdalectomizat 12 pacienţi $\mathrm{cu}$ sindrom Marshall, cu vârste cuprinse între 1 şi 5 ani. Prezentăm două cazuri semnificative din punctul de vedere al metodelor de diagnostic şi tratament.

\section{Cazul 1}

La pacientul 1, episoadele febrile recurente au debutat la vârsta de 8 ani; în perioada decembrie 2018-mai 2019, pacientul a prezentat episoade de

angină acută eritematopultacee, însoţite de adenită laterocervicală, la început şi de stomatită; episoadele apar cu regularitate exact la o lună interval. Pacientul prezintă întotdeauna febră înaltă (peste $39^{\circ} \mathrm{C}$ ), rezistentă la antitermice şi antibioterapie per os. Proba terapeutică este întotdeauna pozitivă, atât simptomele, cât şi markerii inflamatori scăzând dramatic după 2 doze de dexametazonă orală (tabel 1). Intercritic, toate analizele de laborator se normalizează.

Am administrat dexametazonă per os $(2$ doze de câte $8 \mathrm{mg}$ fiecare la 12 ore interval) sau injectabil, cu ocazia celor două internări ale pacientului din această perioadă; uneori, s-a administrat şi antibiotic de acoperire (Cefuroxime sau Zinnat). Aspectul bucofaringoscopic s-a ameliorat, de asemenea, dramatic după cele două doze de cortizon, aspectul de angină acută eritematopultacee dispărând complet după proba terapeutică cu cortizon (figura 1).

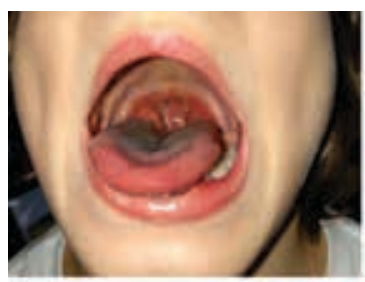

A

FIGURA 1. Ameliorarea dramatică a aspectului bucofaringoscopic după corticoterapie într-un caz de sindrom Marshall. A. Înainte de dexametazonă; B. După 2 doze de dexametazonă

Între mai 2019 şi martie 2020, apare o pauză de 10 luni în care pacientul este complet sănătos; din martie 2020 reîncep cu regularitate episoadele febrile de angină acută; probele inflamatorii intens pozitive în puseu, febra înaltă.

După 2 astfel de recurenţe, se propune şi se practică adenoamigdalectomia, cu evoluţie favorabilă; se constată absenţa episoadelor febrile recurente în următoarele 9 luni postamigdalectomie.

\section{Cazul 2}

Cel mai tânăr pacient diagnosticat cu sindrom Marshall la noi în clinică a fost în vârstă de 10 luni.

TABEL 1. Variația numărului de leucocite, monocite, neutrofile şi CRP în episoadele febrile la pacientul 1, înainte şi după administrarea a două doze de dexametazonă

\begin{tabular}{|c|c|c|c|c|}
\hline Data recoltării & $\begin{array}{c}\text { Leucocite } \\
\text { (VN: } 4.500-13.500 / \mu \mathrm{l})\end{array}$ & $\begin{array}{c}\text { Monocite } \\
\text { (VN: } 0-1.000 / \mu \mathrm{l}) \\
\end{array}$ & $\begin{array}{c}\text { Neutrofile } \\
\text { (VN: } 1.800-8.000 / \mu \mathrm{l}) \\
\end{array}$ & $\begin{array}{c}\text { CRP } \\
\text { (VN: } 0-5 \mathrm{mg} / \mathrm{l}) \\
\end{array}$ \\
\hline 18.02.2019 & $13.300 / \mu \mathrm{l}$ & $1.690 / \mu \mathrm{l}$ & $10.541(79 \%)$ & 150,63 \\
\hline 20.02 .2019 & $4.450 / \mu \mathrm{l}$ & $730 / \mu \mathrm{l}$ & $1.690(38 \%)$ & 18,21 \\
\hline 18.03.2019 & $14.190 / \mu \mathrm{l}$ & $2.580 / \mu \mathrm{l}$ & $8.820(62 \%)$ & 131,27 \\
\hline 22.03 .2020 & $12.570 / \mu \mathrm{l}$ & $2.050 / \mu \mathrm{l}$ & 7.930 (63\%) & 102,12 \\
\hline
\end{tabular}


TABEL 2. Variația numărului de leucocite, monocite, neutrofile şi CRP în episod febril la pacientul 2, înainte şi după administrarea unei doze de dexametazonă

\begin{tabular}{|c|c|c|c|c|}
\hline Data recoltării & $\begin{array}{c}\text { Leucocite } \\
\text { (VN: } 6.000-17.000 / \mu l)\end{array}$ & $\begin{array}{c}\text { Monocite } \\
\text { (VN: } 0-1000 / \mu l)\end{array}$ & $\begin{array}{c}\text { Neutrofile } \\
\text { (VN: } 1.800-8.500 / \mu \mathrm{l})\end{array}$ & $\begin{array}{c}\text { CRP } \\
\text { (VN: } 0-5 \mathrm{mg} / \mathrm{l})\end{array}$ \\
\hline 16.01 .2021 & 17.210 & $2.110(12,3 \%)$ & $10.580(61,5 \%)$ & 247,45 \\
\hline 18.01.2021 & 20.850 & $2.260(10,8 \%)$ & $8.280(39 \%)$ & 153,17 \\
\hline
\end{tabular}

Din anamneză, a reieşit că pacientul prezenta episoade febrile recurente (de angină acută eritematoasă sau eritematopultacee) o dată la 3 săptămâni de la vârsta de 5 luni, cu proba terapeutică pozitivă de 2 ori (răspuns dramatic la administrarea de dexametazonă orală $1 \mathrm{mg} / \mathrm{kgc}$ în două zile succesive). Analizele de laborator în cazul unui episod febril acut recent (cu angină acută eritematopultacee şi adenită laterocervicală) arată probe inflamatorii crescute, acestea răspunzând semnificativ la prima doză de dexametazonă administrată ambulator (tabel 2).

Febra scade după această primă doză, dar revine; pacientul se internează şi i se administrează injectabil a doua doză de dexametazonă (împreună cu antitermice şi antibioterapie de protecţie cu Ceftriaxone), după care simptomatologia dispare complet.

Ca urmare a vârstei mici a pacientei, nu s-a indicat adenoamigdalectomie în acest caz, optându-se de comun acord cu pediatrul curant pentru tratarea fiecărui episod febril cu cortizon; s-a inceput administrarea pe termen lung de Montelukast. După primele două luni de tratament, simptomele nu au reapărut.

\section{DISCUȚII}

Primul caz descris este un caz tipic de sindrom Marshall, exemplificând diagnosticarea sindromului prin proba terapeutică şi răspunsul bun la amigdalectomie. Interesantă şi inexplicabilă este perioada de 10 luni în care recurenţa episoadelor febrile la pacientul nostru a încetat. Unii autori constată apariţia simultană a episoadelor la copiii gemeni, considerând că sindromul poate fi influenţat de factorii de mediu la copiii predispuşi genetic (14); este posibil ca unii factori de mediu să fi jucat un rol în dispariţia simptomelor timp de 10 luni la pacientul nostru.

Particularitatea primului caz a constat în debutul tardiv al episoadelor febrile recurente (la 8 ani) şi în perioada de 10 luni de acalmie a simptomatologiei.

Al doilea caz este un caz este un caz extrem prin vârsta mică a pacientului; tratamentul propus în fiecare caz trebuie individualizat; este însă prea devreme pentru a trage o concluzie în ceea ce priveşte eficienţa tratamentelor alternative (cu inhibitori de leucotriene) în acest sindrom $(2,4,12)$.
Diagnosticul sindromului Marshall este un diagnostic clinic de excludere. De obicei, stabilirea unui astfel de diagnostic necesită un timp îndelungat - la debut, afecţiunea poate trece drept o angină acută infecţioasă (tratată în consecinţă cu antibioterapie), apoi apar recurenţe, medicul constată că aceste recurenţe sunt periodice şi se ridică suspiciunea de sindrom Marshall; este, de asemenea, necesară o perioadă de timp pentru instituirea probei terapeutice cu cortizon (de obicei, de două sau trei ori înainte de a propune soluţia chirurgicală).

Observăm la toţi pacienţii probele inflamatorii intens pozitive în perioadele febrile (CRP de ordinal sutelor de $\mathrm{mg} / \mathrm{l}$ ), în concordanţă cu datele din literatură $(3,4)$, dar şi ameliorarea rapidă a acestora după administrarea a două doze de cortizon (CRP scade în 2 zile la 20-50 mg/1).

Tratamentul medicamentos folosit de noi a constat în două doze de corticosteroid oral (dexametazonă cp $0,5 \mathrm{mg} / \mathrm{kg} /$ doză) în 2 zile succesive, cu remisia totală a simptomelor la $100 \%$ dintre pacienţi (la unii pacienţi, febra se remite după prima doză de cortizon). În cazul unor pacienţi spitalizaţi, s-a folosit corticoterapia injectabilă.

Amigdalectomia a soluţionat definitiv cazul primului pacient, fapt observat şi în cazul altor 11 pacienţi diagnosticaţi cu sindrom Marshall şi adenoamigdalectomizaţi în serviciul nostru în ultimii 3 ani. S-a constatat, din păcate, reticenţa unor părinţi la sugestia de amigdalectomie, în special în cazul pacienţilor sub 2 ani cu sindrom Marshall.

\section{CONCLUZII}

Diagnosticul de sindrom Marshall este unul clinic; specifice sunt periodicitatea simptomelor şi răspunsul dramatic la corticosteroizi orali.

Tratamentul faringitei acute recurente este controversat: corticoterapia orală este eficientă pe termen scurt, amigdalectomia este eficientă pe termen lung.

Sindromul Marshall trebuie avut în vedere de către toţi specialiştii otorinolaringologi şi pediatri ca posibilitate diagnostică în episoadele febrile recurente, iar amigdalectomia reprezintă o soluţie bună de tratament în aceste cazuri. 


\section{BIBLIOGRAFIE}

1. Berlucchi M, Meini A, Plebani A, Bonvini MG, Lombardi D, Nicolai P. Update on treatment of Marshall's syndrome (PFAPA syndrome): report of five cases with review of the literature; Ann Otol Rhinol Laryngol. 2003 Apr;112(4):365-9.

2. Berlucchi M, Nicolai P. Marshall's syndrome or PFAPA syndrome. Orphanet encyclopedia Yan 2004. Available at: http:/www.orphanet/ patho/GB/uk-PFAPA.pdf.

3. Marshall GS, Edwards KM, Butler J, Lawton AR. Syndrome of periodic fever, pharyngitis and aphtous stomatitis. J Pediatr 1987;110:43-46.

4. Esposito S, Bianchini S, Fattizzo M, Baggi E, Marchisio P, Rigante D. The enigma of periodic fever, aphthous stomatitis, pharyngitis and adenitis syndrome. Pediatr Infect Dis J. 2014 Jun;33(6):650-2.

5. Feder HM Jr. Periodic fever, aphtous stomatitis, pharyngitis, adenitis: a clinical review of a new syndrome. Curr Opin Pediatr. 2000;12:253256.

6. Forsvoll J, Oymar K. The role of tonsillectomy in Periodic Fever, Aphtous stomatitis, Pharyngitis and cervical Adenitis syndrome; a literature review. BMC Ear Nose Throat Disord. 2018;18:3.

7. Renko M, Lantto U, Tapiainen T. Towards better diagnostic criteria for periodic fever, aphtous stomatitis, pharyngitis and adenitis syndrome, Acta Paediatr. 2019 Aug;108(8):1385-1392.

\section{Conflict of interest: none declared}

Financial support: none declared
8. Padeh S, Stoffman N, Berkun Y. Periodic fever accompanied by aphtous stomatitis, pharyngitis and cervical adenitis syndrome (PFAPA syndrome) in adults. Isr Med Assoc J. 2008 May; 10(5):358-60.

9. Vanoni F, Theodoropoulu K, Hofer M. PFAPA syndrome: a review on treatment and outcome. Pediatric Rheumatology 2016;14:38.

10. Lee WI, Yang MH, Lee KF, Chen LC. PFAPA syndrome (periodic fever, aphtous stomatitis, pharyngitis, adenitis). Clin Rheumatol. 1999;18:207-213.

11. Padeh S, Brezniak N, Zemer D, Pras E, Livneh A, Langevitz P, Migdal A, Pras M, Passwell JH. Periodic fever, aphtous stomatitis, pharyngitis and adenopathy syndrome: clinical characteristics and outcome. J Pediatr. 1999 Jul;135(1):98-101.

12. Scimeca PG, James-Herry AG, Weinblatt ME. Atypical PFAPA syndrome in a young girl with Fanconi anemia. $J$ Pediatr Hematol Oncol. 1996 May;18(2):159-61.

13. Abramson YS, Givner LB, Thompson JN. Possible role of tonsillectomy and adenoidectomy in children with recurrent fever and tonsillopharyngitis. Pediatr Infect Dis J. 1989;8:119-120.

14. Sampaio IC, Rodrigo MJ, Monteiro Marques JG. Two siblings with periodic fever, aphtous stomatitis, pharyngitis, adenitis (PFAPA) syndrome. Pediatr Infect Dis J. 2009 Mar;28(3):254-5. 